I submit that in tabes each part of the body should be studied in detail, as it is the "field of symptoms "-as each case is a series of more or fewer sub-maladies" - that it is well, for example, to analyse separately the "crises," the abnormal pupillary conditions, the ataxic gai $t$, \&c., before we deal with the different sub-maladies we encounter in single cases, as together making ap a more or less Componnd Malady owing to one kind of disease-destruction the result of one kind of pathological process- of intrinsic and extrinsic elements of different regions of the lowest level. And I submit that tabes should not be spoken of as being owing to disease of the cord, but as resulting from disease of intrinsic and of extrinsic elements of different regions, often supraspinal as well as spinal, of the lowest level.

\section{A SUCCESSFUL CASE OF PYLOROPLASTY.}

BP RUTHERFORD MORISON, M.B. EDIN., F.R.C.S. FNG. AND EDIN.,

SENIOR ASSISTANT SURGEON, ROYAI INFIRMART, NEWCASTLE-ON-TYNE.

A WOMAN aged forty-eight years was sent by Mr. Sheraton of Sedgefield to consult Dr. Drummond, who placed her ander my care. The patient was suffering from vomiting and gastric pain. Her illness had commenced five years previously with an attack of vomiting. Similar attacks recurred every three months or so. Since the first seizure she had been unable to take any but the lightest forms of food. Beef or any heary meal brought on an attack. In the early part of last year the attacks of sickness became more frequent and were accompanied by pain. Since the middle of July, 1894, she had been a complete invalid, with the following symptoms: For two or three days, provided she took very little food and that only of a liquid or farinaceous kind, she would feel fairly well ; then a "lump" would gradually form in the umbilical region, producing isensations similar to those experienced during the later stages of pregnancy when the child is moving vigorously about. The "lump" after a time became hard and painful, and violent romiting accompanied the pain. After lasting for two or three days these troubles disappeared, and for a short time relief was obtained, so that each week was divided into two nearly equal periods-one of pain and sickness, the other of comparative ease. The vomited matter had a frothy, yeasty appearance, an offensive odour, and in quantity always exceeded what had been taken. Farly in July :she ate a small portion of cabbage, and for three days afterwards she noticed traces of it in the vomited matter. Latterly she had observed that the romit contained material like coffee grounds and that her stools were black. Her previous health had been good except for a liability to indigestion, more marked during the last twenty years. She had had seven children and one miscarriage. A sister had died from phthisis at the age of twenty-six years. There was nothing else worthy of note in her family history. On Oct. $6 \cdot \mathrm{h}$, T897-i.e., two days after coming to $N \in w c a s t l e-t h e$ ordinary vomiting attrack came on. Nothing was allowed by the month, and nutrient enemata were ordered. On the 7 th the patient vomited, from $3 \mathrm{~A}$ ir. to $10 \mathrm{P} . \mathrm{N}$, three pints of yeasty, fetid, brownish fluid. She had passed a restless night. On ite 8 th she romited about ten ources of blood. The nutrient - eremata were ordered to be continued. On the $9 \mathrm{ch}$ she romited some blood at 11 A.M., just before I saw ber for the Sirst time. Dr. Drummond and I agreed to wash the stomach out. This was done at 2 P.Mr. Imme iately after washing a small quantity of milk, barley water, and brandy were administered. There was no more vomiting at the time. The fluid remored from the stomach was brown in colour with a fetid, yeasty odour, and contained changed blood. F:om this time to the date of the operation the treatment - consisted of daily stomach lavage, the frequent administration of small quantities of liquid nourishment by the mouth, and the $u$ ue of nutrient enemata. On Oct. 15th the following note was made of her condition: "The patient is much emaciated and weigbs only 5 st. $1 \mathrm{lb}$; ; she bas no appetite; the complexion is sallow and the expression anxious; the abdomen is retracted and flat except orer the epigastric, left byperobongriac, left nmbilical, and left lumbar regions, which are elevated by the distended and dilated stomach, the shape of which can be fairly made out through the thin and flaccid abdominal walls. On palpation succussion sounds are elicited, and just above the umbilicas and immediately to the right of the middle line a firm nodule the size of a walnut is to be felt. After the stomach has been emptied by the tube the nodule can be picked up between the finger and thumb. It is movable in every direction and when pressed directly backwards has pulsation communicated to it by the aorla. Percussion corroborates the belief that the stomach is much

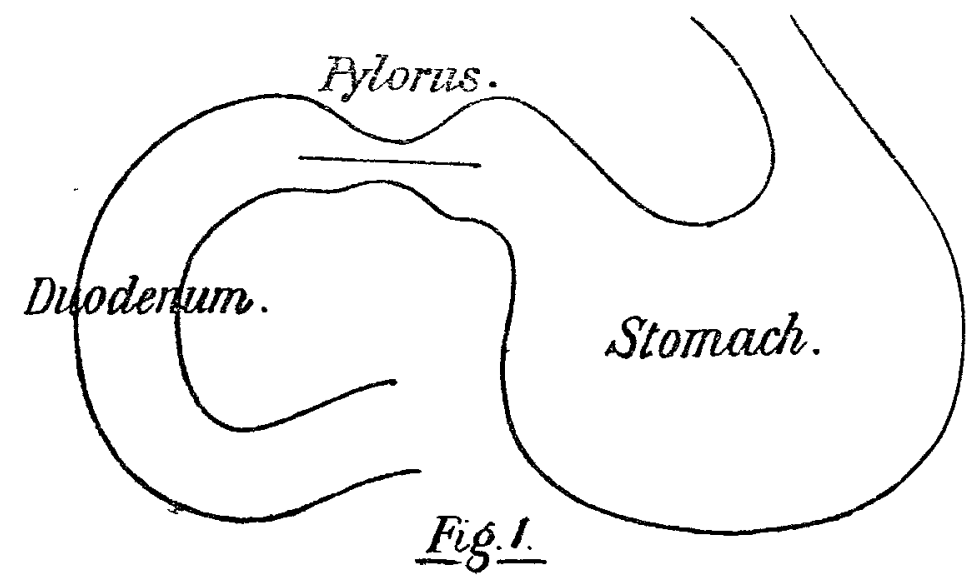

dilated. All the other organs of the body appear to be healthy." On Oct. 16th the Heincke-Mickulicz operation was performed. On opening the abdomen the nodule described was found, as was anticipated, to be the pylorus. Taken between the finger and thumb it felt thickened and resisting, as if an indiarubber ring was embedded in it. The stomach was opened one inch above the pylorus and an attempt made

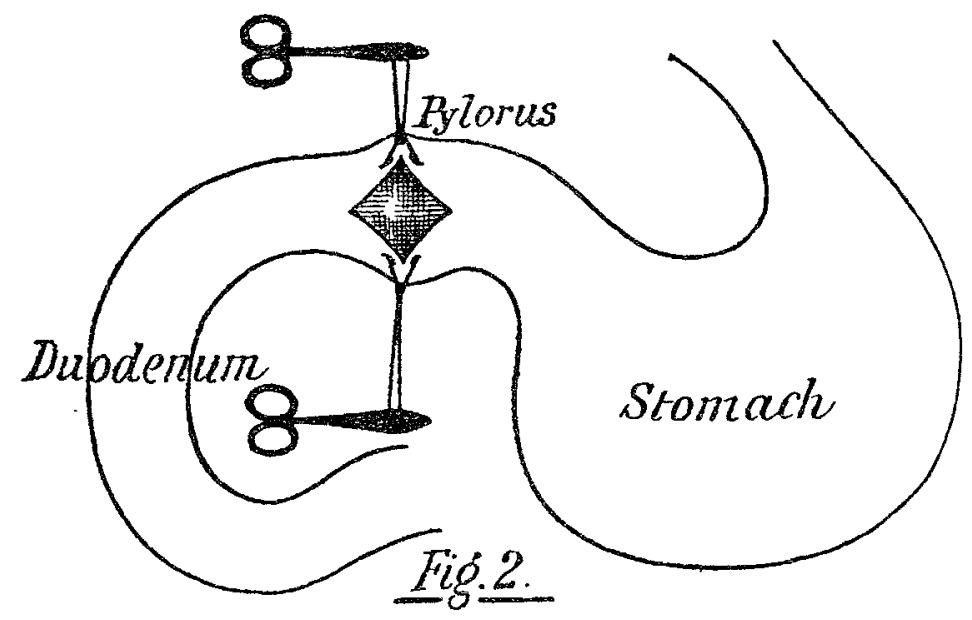

to pass the little finger through this opening into the pylorus. The pyloric orifice was, however, found to be so small that neither the little finger nor a pair of small clip forceps, closed and introduced subsequently, would pass through it. The incision made in the stomach was then prolonged with scissors through the middle of the exposed anterior portion of the pyloras for about an inch into the

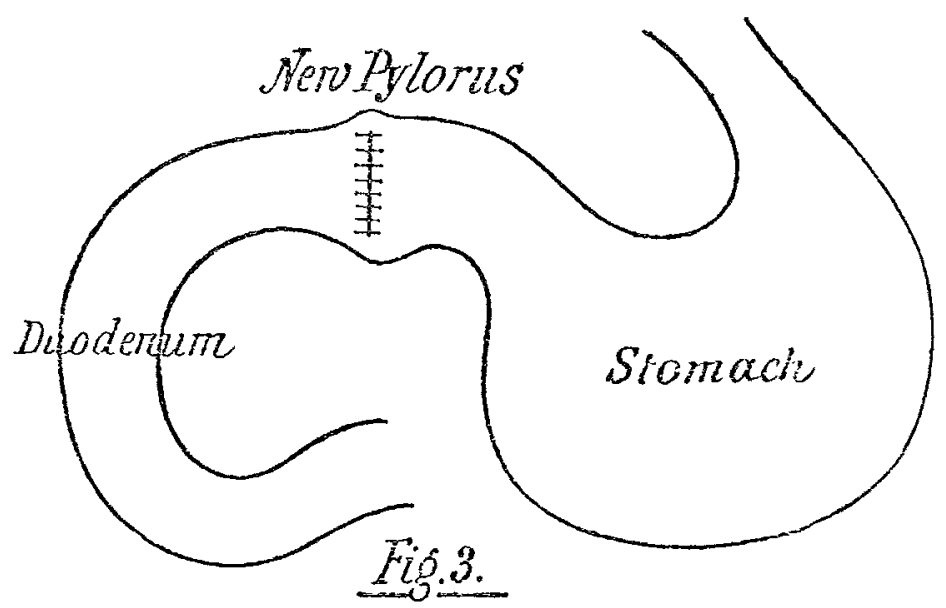

duodenum. (Fig. 1) The pyloric ring was firm and thick. There was no evidence of old nlcer, scar, or puckering. Drawing apart the middle of each side of the longitudinal incision converted it into a transverse one. (Fig. 2.) This position was permanently secured by a first row of sntures passed close to the edges of the incision through all the 
crats of the stomach and duodenum, and a second row through the peritoneum only, in Lembert fashion, burying the first. (Fig. 3.) The operation was completed by closing the abdomen in the ordinary way, and occupied half an hour. The patient, notwithstanding her feeble condition, stood it well. Immediately after being put to bed she was slightly sick. For the first twenty.four hours nothing was given by the moath. Nutrient enemata were administered every two hours. Twenty-eight hours after the operation teaspoonfuls of hot water were given occasionally. On the third day small quantilies of barley-water and milk were given by the mouth and the nutrient enemata were continued. Oa the evening of this day, after having barley-water and milk, she felt a pain "as if the fluid was passing over a raw surface out of her stomach." On the fourth day she had arrowroot and milk, with mutton broth. On the sixth day she complained of feeling hangry, a sensation she had not experienced for years. On the tenth day the dressing was removed for the first time and the wound was found to be entirely healed. at this time she was having regular meals of bread-andbutter, tea, eggs, fish, and potato. During her convalescence the pulse and temperature never rose above normal, and she made steady progress from the day of the operation.

On Nov. 8th (three weeks after the operation) the patient Was shown at a meeting of the Northumberland and Durham Medical Society. She was then in good health and weighed $6 s^{t} .1$ lb. (a gain of 1 st.). On Jan. 21st, 1895, she writes: "I am glad to say I am keeping very well, and I weigh 8 st. $6 \mathrm{lb}$. I don't think I ever weighed so much in my life, and nothing disagrees with me."

Serrastle-on-Tyne,

\section{CASE OF GENERAL PARALYSIS OF THE INSANE IN A CHILD.}

BY JOHN THOMSON, M.D., F.R.C.P. EDIN.,

IXTRA PHYSICIAN TO THE ROYAL HOSPITAL EOR SICK CHILDREN, EDIKBDRGH

AVD

W. R. DAWSON, M.D. DUBL.,

SEMOYSTRATOR OF PATHOLOGY, ROYAL COLLEGE OF SURGEONS IN IRELATD.

THE following is the record of a case of general paralysis, beginning at the very nnosually early age of ten years and eight months in a girl of average intellect, running a course similar to that most commonly observed in women, and ending in death after a steady breaking down of the bodily and mental powers during a period of two years and four and a half months. An interesting point in the clinical history was the presence for about six months of very marked "facial irritability" (Chvostek's symptom). We have recently observed this symptom in another case of developmental general paralysis-a young woman aged about twenty yearsand in a case of ordinary general paralysis. In many of the cases of general paralysis beginning in early life that have been reported, congenital syphilis has been looked upon as an important etiological factor. ${ }^{2}$ Whether it was so in the present instance must remain an open question, for, although we csuld obtain no decisive facts, our investigations left a strong impression on our minds that the presence of syphilis in the parents was quite within the range of possibility. The post-mortem appaarances were perfectly typical of advanced general paralysis and put the nature of the case beyond a donbt.

The patient, a girl aged eleven years and five montbs, was brought to the Dispensary of the Royal Hospital for Sick Clidren, Edinburgh, on Dec. 7th, 1892. Her mother complained that her daughter was very nervous-constantly shaking-and that she was quite unable to do any lessons. The condition had lasted for more than nine months. The fatler ras a strong, healthy-locking man. He admitted that he occasionally drank too much, but denied having ever bid any renereal disease. There was no history of nervous or reertal disease in bis family. The mother was nervous ard excitable; she had the reputation among her neighbours of being intemperate. Her mother's brother became insane

1 1). Thomson is responsible for the clinical, and Dr. Dawson for the To.tigical, notes.

C. usto. Neuroses of Development, p. 75. Middlemass ; Journal Yrinal Science, January, 1894. in old age. The patient was the youngest of seven children. One had died from hydrocephalus; two (immediately preceding the patient) were stillborn; the other three were alive, and healthy with the exception of the eldest, who suffered from "abscesses." None of the children had had snuffles or a rash during early infancy. There had been no miscarriages. The mother had good health during pregnancy. The child had no symptoms suggestive of syphilis as an infant, and she had always been looked upon as strong and healthy. Her mother said she was "the most easily brought up of her children," and that she never had any bad habits or mental peculiaritiss. She was a natural, bright, affectionate child, who did her lessons fairly well and took a good place at school.

Nine months before I (Dr. Thomson) saw her she had been promoted by the schoolmaster of the Board School from the fourth to the fifth standard after some sort of an examination. At that time, apparently, nothing abnormal had been noticed about her by anybody. Shortly after beginning the work of the higher standard, it was noticed that she was quite unequal to it and seemed to be getting less and less intelligent. She was, therefore, after a few weeks, put back into her former class. She was then found by the teacher who had taught her before to have changed very much in her capacity, and to have become so stupid that she could scarcely be taught anything at all and had forgotten a great deal of what she knew quite well before. She could not do the very simplest sums, and it seemed to be impossible to teach her even a single line of poetry by heart. It was also noticed that her speech was slower than it used to be, and that her handwriting was worse, the strokes being "thin and like a saw." At home it was also seen that she was ge'ting more stupid. She had to be told over and over again to do simple things and had to be shown exactly how to do them or she did them wrong-e.g., she tried one day to sweep the floor with the wrong end of the broom. If sent with a message she forgot it unless she repeated it over and over again to herself on the way. Her hands were very unsteady ; she often let cups fall, and she dropped her stitches when she tried to knit. No cause could be assigned for the onset of her illness. She had become steadily worse on the whole, although she was sometimes brighter than at other times.

The following are the notes taken at the time:"On examination the child is found to be fairly well nourished, but under-sized and poorly developed. Her height is $47 \frac{1}{2}$ inches and her weight 4 st. $\frac{1}{2} \mathrm{lb}$. No sign of congenital syphilis can be found. The cranium is normal in size and hape. A prominent ridge is felt in the position of the frontal suture. The palate is somewhat high, but not very abvormal. The teeth also are not abnormal in shape, and the ears are well formed. There is a marked absence of expression about the upper part of her face. The heart, lungs, and abdominal organs are normal. The pulse is 96 to 100 and regular. Her attitude and gait are peculiar. She stands with her shoulders forward and her arms hanging down in front. She always keeps her hands closed pretty tightly, gecerally over a penny or some other small object, and her mother has difficulty in opening them when she is washing her. In walkirg she keeps her legs rather far apart, bends her knees rery little, and takes small steps. As one of her neighbonrs says, she 'walks like a baby.' Her muscular movements are accompanied by a coarse tremor. This is very distinctly seen in her hands if she tries to do anything with them or to hold them still and extended; and its traces are very noticeable in her writing, which is very characteristic. The tremor is also extremely marked in her tongue when she protrudes it, and in her lips and lower jaw at the same time. When she puts ont her tongue she tries to steady it by compressing her lips tightly upon it. Her voice is slow and hesitating and distinctly suggestive of general paralysis. Her eyes have been examined by Dr, E. E Maddox, who finds sufficient hypermetropia present to account for her convergent squint and also for her rather small pupils. The pupils react very slowly and only slightly to both light and accommodation. The left is somewhat larger than the right, and both are somewhat irregular in outline. Owing to the child's extreme restlessness and the smallness of her pupils it is found impossible to get a good view of the fundus, but nothing abnormal can be seen. The child is somewhat deaf, especially on the left side. In other respects the special senses seem normal. The knee-jerks are present equally, but not strongly, on both sides. Her mental condition is very dull. She has to be 